\title{
EXPERIMENTAL RESEARCH OF CEREBROPROTECTIVE ACTIVITY OF THE NEW 4-AMINOBUTATANOIC ACID DERIVATIVE
}

\author{
Oksana Mishchenko \\ Department of Clinical Pharmacology ${ }^{l}$ \\ mishchoksana@gmail.com \\ Natalia Palagina \\ Department of Clinical Pharmacology ${ }^{l}$ \\ palaginanatasha@ukr.net \\ ${ }^{I}$ National University of Pharmacy \\ 53 Pushkinska str., Kharkiv, Ukraine, 61002
}

\begin{abstract}
The aim. To study the cerebroprotective activity of a new derivative of 4-aminobutanoic acid the compound KGM-5 on the effect on survival and behavioural responses, cognitive impairment and neurological deficits in rats with acute cerebrovascular accident.

Materials and methods. Acute cerebrovascular accident (ACVA) was simulated in rats by irreversible unilateral carotid occlusion (UCO) under anesthesia with sodium thiopental (35 mg/kg, intraperitoneally, IP). Five groups of animals were used: intact control (IC, $n=6$ ), a group of animals with ACVA, which were not treated (control pathology, CP, $n=13$ ); group of animals with ACVA, which were treated for 5 days after surgery (first injection 30 min before surgery) with the compound KGM-5 (ACVA+KGM-5, $n=14$ ) at a conditionally effective dose of $30 \mathrm{mg} / \mathrm{kg}$ body weight of animals, a group of animals with ACVA (ACVA+CD «Picamilon», $n=13$ ), who received IP for 5 days, the comparison drug (CD) «Picamilon» at a dose of $17 \mathrm{mg} / \mathrm{kg}$ and pseudo-operated animals (POA), $n=8$ ), which were operated without ligation of the carotid artery, which allows to level the effect of anesthesia and surgery on the studied indicators. The cerebroprotective effect of the studied agents was assessed by an integral criterion - survival of animals (throughout the experiment), indicators of neurological deficit (24, 48, 72, 94 hours after ACVA modelling), the state of cognitive functions in the test of extrapolation escape test (EET) (72 hours after ACVA modelling)

Results. The KGM-5 compound contributed to a significant reduction in the severity of neurological deficit, as evidenced by significant differences in this indicator compared with $\mathrm{CP}$, respectively, the first ( 0.5 points vs. 1.25 points, $p<0.05)$, the third $(0.0$ points against 1.0 point, $p<0.05)$ and the fourth day $(0.0$ points vs. 0.5 points, $p<0.05)$ after OCO. Under the influence of $\mathrm{CD}$ «Picamilon» reduction of neurological deficit compared with CP was observed on the first, third and fourth days, but these differences were insignificant $(p>0.05)$. Both studied agents - the compound KGM-5 and CD «Picamilon» contributed to the improvement of cognitive functions of rats with ACVA, as evidenced by a significant reduction $(p<0.05)$ of the latent period of diving in the EET, respectively, 1.8 and 1.7 times compared with CP and did not show a significant effect on animal survival.

Conclusion. The cerebroprotective activity of a new 4-aminobutanoic acid derivative in the conditions of acute cerebrovascular accident in rats was established in terms of the ability to reduce the severity of neurological deficits and improve cognitive functions in the extrapolation escape test. The severity of cerebroprotective activity of the new compound is not inferior to GABA-ergic drug «Picamilon».
\end{abstract}

Keywords: new derivative of 4-aminobutanoic acid, acute cerebrovascular accident in rats, cerebroprotective activity.

DOI: $10.21303 / 2504-5679.2021 .001851$

\section{Introduction}

Cognitive disorders are one of the most important medical and social problems of modern society. There are about 50 million people in the world who suffer from various forms of dementia. The number of patients with severe cognitive impairments doubles every ten years, and by 2050 the total number of patients on Earth with this disease will reach 130 million [1, 2]. The main diseases of the brain that contribute to the development of cognitive dysfunction are neurodegenerative (Alzheimer's disease, etc.), vascular (cerebral ischemia), traumatic brain injury, neuroinfections and others $[1,3,4]$. Cerebrovascular disorders are the second most common cause of dementia after Alzheimer's disease. Vascular dementia occupies from 10 to $30 \%$ in the overall structure of 
dementia $[1,4,5]$. Vascular disorders lead to changes in cerebral blood flow with the development of hypoxia of brain tissues, disruption of nutrition and energy supply of neurons, which contributes to the development of intracellular biochemical changes and diffuse multifocal brain damage. The latter leads to the development of cognitive disorders [6-8]. For the treatment of cognitive disorders in complex therapy are widely used cerebroprotectors, nootropics, which are not always effective and safe [9-12]. In this regard, the search for new nootropic drugs that can improve cognitive impairment resulting from acute or chronic cerebral circulatory disorders is an urgent scientific task. Promising in this regard are new derivatives of 4-aminobutanoic acid, synthesized at the National University of Pharmacy, among 11 of which was selected the leading substance for antiamnestic activity under the conditional name KGM-5, which also exhibits antihypoxic activity [13]. Given the above, it is advisable to study its ability to improve cognitive impairment and neurological deficits resulting from acute cerebrovascular accident.

The aim. To study the cerebroprotective activity of a new derivative of 4-aminobutanoic acid, the compound KGM-5, on the effect on survival and behavioural responses, cognitive impairment and neurological deficits in rats with acute cerebrovascular accident.

\section{Materials and methods}

In the experiment, white adult non-linear male rats weighing $200 \pm 20 \mathrm{~g}$ were used [14]. Rats were divided into groups that were formed by randomization using body weight as the main feature. The research was conducted on the basis of the Educational and Scientific Training Center for Medical and Biological Research of the Educational and Scientific Institute of Applied Pharmacy of the National University of Pharmacy (NUPh) in the spring of 2020, natural light regime «day and night», in standard cages, on a standard diet.

All manipulations with animals were carried out in accordance with GLP requirements, recommendations of the State Expert Center of the Ministry of Health, General Ethical Principles of Animal Experiments (Ukraine, 2001), Law of Ukraine of February 21, 2006 No. 3447-IV as amended «On the protection of animals from cruel treatment», the decision of the First National Congress on Bioethics (Kyiv, 2007) and the European Convention for the Protection of Vertebrate Animals Used for Experimental or Other Scientific Purposes [15].

Гостре порушення мозкового кровообігу (ACVA) моделювали у щурів шляхом незворотної односторонньої каротидної оклюзії (UCO) [16]. To reproduce the ACVA model, the animals were anesthetized with sodium thiopental (35 $\mathrm{mg} / \mathrm{kg}$, ip), fixed in the supine position, the hair on the neck was removed, and the soft tissues of the neck were dissected by blunt cutting off the fascia. The left common carotid artery was isolated, connective tissue and nerve trunks were separated around it, ligatures were brought under the vessel and it was ligated. The wound was sutured in layers and treated with antiseptic ( $0.05 \%$ solution of chlorhexidine bigluconate). All the above manipulations were performed with pseudo-operated animals (POA, $n=8$ ), except for ligation of the carotid artery, which allows to neutralize the effect of anesthesia and surgery on the studied parameters. A total of 5 groups of animals were used: intact control (IC, $n=6)$, a group of animals with ACVA, which were not treated (control pathology, CP, $n=13$ ); group of animals with ACVA, which were treated for 5 days after surgery (first administration 30 min after surgery) with the KGM-5 compound (ACVA+KGM-5, $n=14$ ) at a conditionally effective dose of $30 \mathrm{mg} / \mathrm{kg}$ of body weight of animals [13] and a group of animals with ACVA (ACVA+CD «Picamilon», $n=13$ ), who received ip for 5 days the comparison drug (CD) «Picamilon» (solution for injection $100 \mathrm{mg} / \mathrm{ml}$, manufactured by JSC «Pharmstandard UfaVITA», Russia) at a dose of $17 \mathrm{mg} / \mathrm{kg}$, which was calculated from the daily dose for humans (200 mg/day) using the coefficient of species sensitivity [17]. The cerebroprotective effect of the studied agents was assessed by an integral criterion - survival of animals (throughout the experiment), indicators of neurological deficit (24, 48, 72,94 hours after ACVA modelling) [17], the state of cognitive functions in extrapolation escape test (EET) (through 72 hours after ACVA modelling) [17]. Neurological deficiency in animals was determined by the McGraw Stroke-Index Scale in the modification of Gannushkina I. V. [17]. The severity of the condition was determined by the sum of points: up to 3 points - mild, 3-7 - moderate, 7 points and above - severe. Animals were tested daily, counting scores. Paresis, paralysis of the extremities, 
tremor, circling behavior, ptosis, lateral position on the side, mobility of animals were noted. Evaluation of the cognitive functions of rats with ACVA was performed in the extrapolation release test [17]. The device for this test is a cylinder made of transparent acrylic plastic, which is installed in a vessel of cylindrical shape of larger diameter and height to fill it with water. A special metal mount holds the cylinder in the center of this tank. During the test, the ability of the animal, previously placed in the inner cylinder, to find a way out of it by diving under its submerged lower edge into the water, as well as the percentage of rats that coped with the task within 3 minutes were observed. For testing, the unit was filled with water at a temperature of $20-25^{\circ} \mathrm{C}$ so that the inner cylinder was immersed in water by $2.5 \mathrm{~cm}$. The rats were placed in a clear plastic cylinder $40 \mathrm{mi}-$ nutes after the introduction of KGM-5 or CD.

The obtained data were expressed as the mean and its standard error. Comparison of data samples after evaluation of the nature of the distribution was performed using ANOVA analysis of variance and Newman-Keils test (for parametric data) or Kruskal-Wallis method and Mann-Whitney test (for non-parametric data). Differences between groups were considered statistically significant at $p<0.05$. Statistica 6 and Excel software packages were used for statistical data processing [18].

\section{Results}

Analysis of the survival of animals with ACVA shows that the maximum death of animals occurred at $24 \mathrm{~h}$ after UCO (Table 1).

Table 1

The effect of KGM-5 and CD «Picamilon» on the survival rates of rats with the ACVA model

\begin{tabular}{lccccc}
\hline \multirow{2}{*}{ Group } & \multirow{2}{*}{} & \multicolumn{4}{c}{ Survival of animals (number/\%) on } \\
\cline { 3 - 6 } & & $\mathbf{2 4} \mathbf{h}$ & $\mathbf{4 8 ~ h}$ & $\mathbf{7 2} \mathbf{~ h}$ & $\mathbf{9 6} \mathbf{~ h}$ \\
\hline Intact control (IC) & 6 & $6 / 100$ & $6 / 100$ & $6 / 100$ & $6 / 100$ \\
Pseudo-operated animals (POA) & 8 & $8 / 100$ & $8 / 100$ & $8 / 100$ & $8 / 100$ \\
Control pathology (CP) & 13 & $8 / 61.5^{* \#}$ & $8 / 61.5^{* \#}$ & $8 / 61.5^{* \#}$ & $8 / 61.5^{* \#}$ \\
ACVA+KGM-5 (30 mg/kg, ip) & 14 & $12 / 85.7^{\#}$ & $12 / 85.7^{\#}$ & $12 / 85.7^{\#}$ & $12 / 85.7^{\#}$ \\
ACVA+CD «Picamilon» (30 mg/kg, ip) & 13 & $10 / 76.9^{* \#}$ & $10 / 76.9^{* \#}$ & $10 / 76.9^{* \#}$ & $10 / 76.9^{* \#}$
\end{tabular}

Note: * - differences are significant versus intact control, $p<0.05$ (Fisher test); \# - differences are significant versus pseudooperated animals, $p<0.05$ (Fisher test); $n$-number of animals

The POA group had $100 \%$ survival. In the CP 8 group of 13 animals survived, i.e. survival was $61.5 \%$, which was significantly lower compared to IC and POA. Under the influence of KGM-5, the survival of the animals was significantly lower compared to POA and was $85.7 \%$ (12 of 14) for 24 hours of the experiment and was so for 4 days of the experiment. Under the influence of $\mathrm{CD}$ «Picamilon», the survival rate of rats with ACVA was $76.9 \%$, which was significantly lower compared to IC and POA ( $p<0.05$ according to Fisher's test).

Cerebral ischemia is a complex of neurological symptoms.

General inhibition and decreased muscle tone, tremor, ptosis, circling behavior, paresis and paralysis of the extremities were particularly pronounced. Neurological deficit according to the McGraw Stroke-Index Scale in untreated animals (CP group) was expressed during the first three days with a maximum on the first day after UCO (Table 2), as evidenced by the probable differences of this indicator compared with IC.

In general, the results correspond to the literature [9]. The absence of neurological disorders (except for mild symptoms in the first 24 hours) in the POA group confirms the adequacy of the model reproduction technique and its specificity. The KGM-5 compound contributed to a significant reduction in the severity of neurological deficit, as evidenced by significant differences in this indicator compared with $\mathrm{CP}$, respectively, the first ( 0.5 points vs. 1.25 points, $p<0.05)$, the third $(0.0$ points vs. 1.0 point, $p<0.05)$ and the fourth day $(0.0$ points vs. 0.5 points, $p<0.05)$ after UCO. Under the influence of CD «Picamilon» reduction of neurological deficit compared with $\mathrm{CP}$ was observed on the first, third and fourth days, but these differences were insignificant. 
Table 2

The effect of KGM-5 on the severity of neurological symptoms in rats with the ACVA model, Me (LQ; UQ)

\begin{tabular}{|c|c|c|c|c|c|}
\hline \multirow{2}{*}{ Groups of animals } & \multirow{2}{*}{$n$} & \multicolumn{4}{|c|}{ Neurological deficit according to McGraw Stroke-Index Scale, points } \\
\hline & & $24 \mathrm{~h}$ & $48 \mathrm{~h}$ & $72 \mathrm{~h}$ & $96 \mathrm{~h}$ \\
\hline Intact control (IC) & 6 & $0(0 ; 0)$ & $0(0 ; 0)$ & $0(0 ; 0)$ & $0(0 ; 0)$ \\
\hline Pseudo-operated animals (POA) & 8 & $0(0 ; 0,5)^{* *}$ & $0(0 ; 0)^{* *}$ & $0(0 ; 0)^{* *}$ & $0(0 ; 0)$ \\
\hline Control pathology $(\mathrm{CP})$ & 8 & $1.25(0.75 ; 1.5)^{*}$ & $1.0(0.5 ; 1)^{*}$ & $1(0 ; 1)^{*}$ & $0,5(0 ; 1)$ \\
\hline ACVA+KGM-5 (30 mg/kg, ip) & 12 & $0.5(0 ; 1) * / * * / \#$ & $0(0 ; 1)$ & $0(0 ; 0)^{* *}$ & $0(0 ; .0)^{* *}$ \\
\hline $\mathrm{ACVA}+\mathrm{CD} \ll$ Picamilon» $(17 \mathrm{mg} / \mathrm{kg}, \mathrm{ip})$ & 10 & $1.0(0.5 ; 1) * / \#$ & $1.0(0.5 ; 1) * / \#$ & $0(0 ; 0,5)$ & $0(0 ; 0)$ \\
\hline$p$ & & 0.0001 & 0.0021 & 0.0075 & 0.0037 \\
\hline
\end{tabular}

Note: $p$ is the level of statistical significance when comparing samples using ANOVA analysis of variance; * statistical significance compared with IC (Mann-Whitney test), $p<0.05$; ** - statistical significance compared with CP (Mann-Whitney test), $p<0.05$; \#-statistical significance compared with POA (Mann-Whitney test), $p<0.05 ; n-$ number of animals

72 hours after ACVA simulation, the state of cognitive functions was assessed in an extrapolation escape test, which characterizes the ability of animals to find a way to get rid of an acute stressful situation [9]. Extrapolation escape test (EET) is used in psychopharmacology as a sensitive method for studying cognitive functions in an acute stressful situation, which is the placement of animals in a cylinder of water. Latent diving period (LDP) or time before the task of deprivation was the studied parameter in this model. It was found (Table 3) that LDP in animals from the POA group was slightly increased compared to IC, but these differences were not significant $(p>0.05)$.

Table 3

The effect of KGM-5 on the cognitive functions of rats in the extrapolation escape test 72 hours after ACVA simulation

\begin{tabular}{|c|c|c|c|}
\hline \multirow[b]{2}{*}{ Groups of animals } & \multirow[b]{2}{*}{$n$} & \multicolumn{2}{|r|}{ Indexes } \\
\hline & & Latent diving period, $s$ & $\begin{array}{l}\text { The number of animals that completed the task } \\
\text { within } 180 \mathrm{~s} / \%\end{array}$ \\
\hline Intact control (IC) & 6 & $108.7 \pm 23.9$ & $5 / 83.3$ \\
\hline Pseudo-operated animals (POA) & 8 & $159.1 \pm 13.9 *$ & $3 / 37.5^{\mathrm{f}}$ \\
\hline Control pathology $(\mathrm{CP})$ & 8 & $114.8 \pm 13.6^{* *}$ & $7 / 87.5$ \\
\hline ACVA+KGM-5 (30 mg/kg, ip) & 12 & $89.5 \pm 15.3 * *$ & $8 / 66.7$ \\
\hline ACVA+CD «Picamilon» $(17 \mathrm{mg} / \mathrm{kg}, \mathrm{ip})$ & 10 & $95.4 \pm 21.5^{* *}$ & $7 / 70.0$ \\
\hline & & $p=0.0425$ & \\
\hline
\end{tabular}

Note: $p$ is the level of statistical significance when comparing samples using ANOVA analysis of variance; * - statistical significance compared with IC (Mann-Whitney test), $p<0.05 ; * *$ - statistical significance compared with CP (Mann-Whitney test), $p<0.05$;

$f$-statistical significance compared to IC (Fisher test), $p<0.05$; $n$ - number of animals

LDP in animals with ACVA model (group CP) was increased compared with LDP in animals from group IC by 1.5 times $(p<0.05)$ and a significant decrease in the proportion of animals that completed the task within $180 \mathrm{~s}$ (37.5\% against $83.3 \%$ in IC group, $p<0.05$, Fisher test), indicating the development of cognitive impairment as a result of ACVA caused by UCO. The compound KGM-5 contributed to a significant $(p<0.05) 1.8$-fold reduction in LDP compared with $\mathrm{CP}$, almost to the level of IC. The comparison drug «Picamilon» also contributed to a significant $(p<0.05)$ 1.7-fold reduction in LDP compared with CP. Therefore, both agents studied improved cognitive function in rats after ACVA modeling.

\section{Discussion}

Under ACVA, a number of pathological disorders, such as decreased cerebral blood flow (energy deficit), glutamate «excitotoxicity», intracellular accumulation of calcium ions, activation of free radical processes («oxidative stress»), gene expression of early response, local inflammatory reac- 
tions, local inflammatory reactions, damage to the blood-brain barrier, necrosis, apoptosis and other forms of neuronal death always develop [5, 19]. Under ACVA, the weakening of GABA-ergic processes is a significant link in the development of chronic disorders and, consequently, the subsequent depletion of neuronal structures of the brain and the development of cognitive impairment and neurological deficit $[10,11,20]$. Gamma-aminobutyric acid (GABA), which is a natural neurotransmitter, is a central link in the implementation of central inhibition processes through interactions with specific GABA receptors in various brain structures. This has a beneficial effect on neuronal energy, neurodynamics, cerebral circulation, a combination of calming and mild psychostimulant action, which results in a positive effect on cerebral hemodynamic, cognitive and neurological functions [20].

It was found that GABA-ergic substances, in particular the drug «Picamilon», can improve blood supply to the brain, improve autoregulation of cerebral blood flow, inhibit the glutamate-calcium cascade, prevent lipid peroxidation and increase the activity of antioxidant systems, provide inhibition of prevent destructive changes in neurons and improve neurological deficit [20]. These data make obvious the prospects for the development of effective neuroprotectors based on GABA-ergic substances, one of which is a new derivative of 4-aminobutanoic acid - a compound codenamed KGM-5, for which proven antiamnestic and antihypoxic activity [13].

In this experiment, the cerebroprotective effect of KGM-5 was assessed by an integral criterion - animal survival (throughout the experiment), indicators of neurological deficits on the McGraw Stroke-Index Scale (24, 48, 72, 94 hours after ACVA modelling), the state of cognitive functions in extrapolation deprivation (EET) tests (72 hours after ACVA simulation).

It was found that the KGM-5 compound at a dose of $30 \mathrm{mg} / \mathrm{kg}$ as well as CD «Picamilon» contributed to some increase in survival of animals compared to $\mathrm{CP}$, but these differences were insignificant. Under the influence of both studied agents, the survival of animals was significantly lower compared to POA ( $p<0.05$ according to Fisher's test).

The KGM-5 compound significantly reduced the severity of neurological deficits, as evidenced by significant differences in this indicator on the first, third and fourth days after UCO compared with $\mathrm{CP}$ in contrast to $\mathrm{CD}$ «Picamilon», which was less influential.

In the EET test, it was found that both agents tested improved cognitive function in rats after ACVA modelling: the KGM-5 compound contributed to a significant $(p<0.05) 1.8$-fold reduction in LDP compared to $\mathrm{CP}$, almost to the level of IC, CD «Picamilon» also contributed to a significant $(p<0.05) 1.7$-fold reduction in LDP compared with CP.

Thus, the obtained results indicate the cerebroprotective activity of a new derivative of 4-aminobutanoic acid of the KGM-5 compound in conditions of acute brain disorder. The severity of cerebroprotective activity of the new compound is not inferior to GABA-ergic comparison drug «Picamilon».

Study limitations. The reliability of data on the ability of KGM-5 to increase animal survival with the ACVA model is limited by the number of animals.

Prospects for further researches. The presence of cerebrotectory activity in KGM-5 compounds under ACVA actualizes the feasibility of studying its effectiveness in other conditions, in particular in traumatic brain injury.

\section{Conclusions}

In conditions of acute cerebrovascular accident in rats, the ability of a new derivative of 4-aminobutanoic acid to reduce the severity of neurological deficits and improve cognitive function in the test of extrapolation deprivation, indicating cerebroprotective activity.

The severity of cerebroprotective activity of the new compound is not inferior to GABAergic comparison drug «Picamilon».

\section{Conflict of interests}

The authors declare that they have no conflicts of interest.

\section{Financing}

None. 


\section{References}

[1] Kamchatnov, P. R., Umarova, Kh. Ya., Chugunov, A. V. (2015). Management of patients with cognitive impairment. Nervous Diseases, 4, 18-22.

[2] Kovalchuk, V. V. (2020). Cognitive dysfunction. Modern view of etiopathogenesis, diagnosis and therapy. Effective pharmacotherapy, 16 (31), 40-52.

[3] Kuznetsova, S. M., Mankovsky, N. B. (2013). Age-related changes in neurotransmitter systems of the brain as a risk factor for cerebrovascular pathology. Journal of Neurology B. N. Mankowski, 2, 5-13.

[4] Surawan, J., Areemit, S., Tiamkao, S., Sirithanawuthichai, T., Saensak, S. (2017). Risk factors associated with post-stroke dementia: a systematic review and meta-analysis. Neurology International, 9 (3). doi: http://doi.org/10.4081/ni.2017.7216

[5] Sahathevan, R., Brodtmann, A., Donnan, G. A. (2011). Dementia, Stroke, and Vascular Risk Factors; a Review. International Journal of Stroke, 7 (1), 61-73. doi: http://doi.org/10.1111/j.1747-4949.2011.00731.x

[6] Kovalchuk, V. V., Barantsevich, E. R. (2017). Chronic cerebral ischemia. A modern view on etiology, diagnostics and therapy. Effective pharmacotherapy, 19, 26-32.

[7] Fedin, A. I. (2014). Selected Lectures on Outpatient Neurology. Moscow: AST 345, 128.

[8] Mufson, E. J., Binder, L., Counts, S. E., DeKosky, S. T., deToledo-Morrell, L., Ginsberg, S. D. et. al. (2012). Mild cognitive impairment: pathology and mechanisms. Acta Neuropathologica, 123 (1), 13-30. doi: http://doi.org/10.1007/s00401-011-0884-1

[9] Belskaya, G. N., Chuprina, S. E., Vorobyev, A. A., Gorozha, E. N., Butorakina, T. L., Sokolov, M. A., Izmaylov, I. A. (2016). Cognitive disorders in stroke patients: the possibilities of pharmacological correction. Zhurnal Nevrologii i Psikhiatrii Im. S. S. Korsakova, 116 (5), 33-37. doi: http://doi.org/10.17116/jnevro20161165133-37

[10] Mishchenko, T. S., Zdesenko, I. V., Linskaya, A. V., Mishchenko, V. N. (2011). New targets for therapeutical impact in patients with chronic brain ischemia. International Journal of Neurology, 2 (40), 7-13.

[11] Morozova, O. G. (2013). Nootropics in the complex therapy of chronic cerebral ischemia: mechanisms of action and therapeutic possibilities of pramiracetam. International Journal of Neurology, 5 (59), 143-148.

[12] Yevtushenko, E. S. (2013). Nootropics and neuroprotectors in modern clinical neuropharmacology. International Journal of Neurology, 3 (57), 20-27.

[13] Mishchenko, O. Ya., Golik, M. Yu., Hrytsenko, I. S. Komisarenko A. M., Palahina, N. Yu., Mishchenko, M. V. (2017). Pat. No. 120512 UA. Application of 4-aminobutanoic acid derivatives as antiamnestic agents. MPK: A61K 31/197 (2006.01), A61P 25/00. No. u201703627; declareted: 13.04.2017; published: 10.11.2017, No. 21.

[14] Preclinical study of the specific activity of potential drugs of primary and secondary neuroprotection (2016). Kyiv: LLC «Yuston Publishing House», 80.

[15] Pro zatverdzhennia Poriadku provedennia doklinichnoho vyvchennia likarskykh zasobiv (2009). Nakaz MOZ Ukrainy No. 944. 14.12.2009. Available at: https://zakon.rada.gov.ua/laws/show/z0053-10\#Text

[16] Mironov, A. N. (Ed.) (2012). Rukovodstvo po provedeniyu doklinicheskih issledovaniy lekarstvennyih sredstv. Moscow: Grif i K, 944.

[17] Deiko, R. D., Shtrygol, S. Yu., Kolobov, A. A., Mishchenko, O. Ya. (2015). The correction of neurological and cognitive disorders on the model of cerebral ischemia using original neuroactive oligopeptides. Pharmacology and drug toxicology, 1 (42), 24-29.

[18] Petri, A., Sabin, K. (2015). Visual medical statistics. Moscow: GEOTAR-Media, 216.

[19] Gantsgorn, E. V., Khloponin, D. P., Maklyakov, Yu. S. (2013). Pathophysiological basics of acute brain ischemia modern pharmacotherapy. Nootropics and antioxidants' role in neuroprotection. Medical Herald of the South of Russia, 2, 4-12.

[20] Burchynskyi, S. H. (2015). GABA-ergic agents in the pharmacotherapy of chronic cerebral ischemia. International Neurologic Journal, 1 (71), 101-105.

Received date 22.03.2021

(C) The Author(s) 2021

Accepted date 17.05.2021

This is an open access article

Published date 25.05.2021

under the Creative Commons CC BY license

How to cite: Mishchenko, O., Palagina, N. (2021). Experimental research of cerebroprotective activity of the new 4-aminobutatanoic acid derivative. EUREKA: Health Sciences, 3, 95-100. doi: http://doi.org/10.21303/2504-5679.2021.001851 